\title{
ORIGINAL ARTICLE \\ Predictors of outcome for urethral injection of botulinum toxin to treat detrusor sphincter dyssynergia in men with spinal cord injury
}

This article has been corrected since advance online publication and an erratum is also printed in this issue.

\author{
JM Soler $^{1}$, JG Previnaire ${ }^{2}$ and N Hadiji ${ }^{1}$
}

Study design: This is a retrospective study.

Objectives: The objective of this study was to determine outcome predictors for urethral injection of botulinum toxin to treat detrusor sphincter dyssynergia (DSD) in patients with spinal cord injury.

Methods: Botulinum toxin type A (100 Units Botox, Allergan) was injected into the external urethral sphincter using a transperineal approach under EMG guidance. Treatment was indicated if DSD was found on urodynamic testing with a post-void residual volume (PVR) above $100 \mathrm{ml}$. Urodynamic tests and cystourethrograms were performed at baseline. Dysuria (scale of 1-5) and PVR (48- $\mathrm{h}$ bladder diary) were evaluated at baseline and 1 month. The outcome was deemed excellent when PVR was equal to or $<100 \mathrm{ml}$ and $20 \%$, and dysuria rated $<3$.

Results: Seventy-two men with tetraplegia and 27 with paraplegia were included. There were significant reductions in PVR (from 227 to $97 \mathrm{ml}$ and $63 \%$ to $27 \%$ ) and dysuria (from 4.3 to 2.3). Excellent outcomes were found in 48 patients (48\%), and the duration of effectiveness was 6.5 months. The need for catheterisation was decreased or eliminated in 18 patients. Vesicoureteral reflux disappeared in some patients. Poor outcome was significantly related to the presence of bladder neck dyssynergia and the absence of detrusor contraction in standard cystometry. Outcome was also related to the severity of DSD, with a strong correlation between PVR before and after injection ( $r=0.58)$. Injections were repeated in 36 patients and yielded similar outcomes in most cases $(89 \%)$.

Conclusions: Detrusor contractions (odds ratio $=8.6$ ) and normal bladder neck activity (odds ratio $=7.1$ ) are strong predictors of excellent outcome.

Spinal Cord (2016) 54, 452-456; doi:10.1038/sc.2015.224; published online 29 December 2015

\section{INTRODUCTION}

Spontaneous voiding can be an alternative to intermittent catheterisation for patients with spinal cord injury (SCI), mainly patients with tetraplegia who are unable to perform self-catheterisation. However, detrusor sphincter dyssynergia (DSD) is a frequent problem, which often prevents complete emptying of the bladder. ${ }^{1,2}$ This can lead to post-void residual urine (PVR), urinary tract infection, upper urinary tract deterioration and autonomic dysreflexia (AD). DSD greatly reduces the quality of life of these patients.

Several medical and surgical procedures have been proposed to treat DSD, with mixed results and some adverse effects. Oral drugs have limited efficacy. Conventional external sphincterotomy used to be carried out, but it was associated with many complications, including haemorrhage requiring blood transfusion in 5-23\% of cases, erectile dysfunction in $3-64 \%$ and revision in $12-26 \%{ }^{3}$ Although new endoscopic sphincterotomy techniques have been reported to be associated with a lower rate of morbidity, other minimally invasive techniques have been developed as an alternative.
Urethral injections of botulinum toxin type A were proposed by Dykstra et al. in 1988 and have since become common place treatment for DSD. ${ }^{1,4-8}$ This treatment has been shown to be effective in $60-100 \%$ of SCI patients, with a duration of effectiveness from $3^{1,8}$ to 6 months $s^{4,7}$ and no significant side effects. Sphincteric stenting is another option with a satisfactory success rate of $75 \%$ at 3 months; however, this technique is also associated with short- and long-term complications. ${ }^{9}$

The reasons for the failure of botulinum toxin injections are not fully understood: detrusor underactivity, ${ }^{1}$ bladder neck dyssynergia (BND) ${ }^{1,7}$ type of DSD and the dose or dilution of the toxin ${ }^{10}$ have been suggested to affect effectiveness. However, few studies have been carried out, and the samples included are generally small.

The aim of this study was therefore to determine predictors of outcome of urethral injection of botulinum toxin to treat DSD in a large sample of patients with SCI. We particularly investigated the impact of bladder neck activity, type of DSD and the presence of detrusor contractions, as well as the level of SCI and the severity of the lesion on outcome.

${ }^{1}$ Laboratoire d'urodynamique et de sexologie_Centre Bouffard Vercelli - Cap Peyrefite, Cerbère, France and ${ }^{2}$ Spinal Department, Centre Calvé, Fondation Hopale, Berck sur mer, France

Correspondence: Dr JG Previnaire, Spinal Department, Centre Calvé, Fondation Hopale, Berck sur mer 62600, France.

E-mail: previnjg@hopale.com

Received 28 March 2015; revised 24 September 2015; accepted 19 October 2015; published online 29 December 2015 


\section{MATERIALS AND METHODS}

\section{Patients}

This was a retrospective study of adult men (over 18 years of age) with SCI who underwent their first single urethral injection of botulinum toxin type A to improve spontaneous voiding, from January 2000 to September 2013. The indication was based upon the presence of DSD on urodynamics and clinical dysuria, with PVR $>100 \mathrm{ml}$. Treatment was given as an inpatient or outpatient procedure.

Once the effectiveness of the treatment had ceased, or if the first treatment was not effective, a second injection was systematically proposed to the patients if it was still indicated.

If the patient was taking oral bladder medication (mainly $\alpha$-blockers), this was not changed during the study.

\section{Pre-injection evaluations}

- The patients' perception of dysuria was rated on a dysuria scale ranging from 1 (absent) to 5 (maximum). The presence of signs of $\mathrm{AD}$ during voiding was also noted (present or absent).

- PVR urine volume was assessed using a bladder scan and a 48 - $\mathrm{h}$ bladder diary. At least four PVR tests were carried out for each patient.

- Urodynamic tests, including detrusor, urethral and rectal pressure recordings were carried out. Cystometry was carried out with a filling rate of $50 \mathrm{ml} \mathrm{min}^{-1}$ and an EMG coaxial needle co axial needle in the external striated sphincter. If detrusor contractions were absent during bladder filling, an ice-water test was performed directly after the standard cystometry. All descriptions and terminologies used are in accordance with the recommendations of the International Continence Society. ${ }^{11}$

- Cystourethrograms were usually performed just after the urodynamic study. During bladder contraction, the bladder neck can either open normally or contract actively, indicating BND.

\section{Injection of botulinum toxin}

The $100 \mathrm{U}$ of botulinum toxin type A (Botox, Allergan, Irvine, CA, USA) was diluted with $4 \mathrm{ml}$ of $0.9 \%$ saline. Disposable EMG-guided needles $(75 \mathrm{~mm}$, 22-gauge) that allow simultaneous EMG recording and injection were used. Injections were performed with the patient lying supine on a couch.

The needle was inserted into the perineum, $1 \mathrm{~cm}$ right of the midline and $2 \mathrm{~cm}$ above the anal margin. A gloved finger in the rectum monitored the position of the prostate, and the electrode was directed towards its apex under EMG guidance. An amount of $2 \mathrm{ml}(50 \mathrm{U})$ was injected, and then the same procedure was applied on the left side $(1 \mathrm{~cm}$ left of the midline) with another $2 \mathrm{ml}(50 \mathrm{U})$.

\section{Outcome}

All patients underwent clinical follow-up at 1 month. This included the dysuria scale, the 48- $\mathrm{h}$ bladder diary and evaluation of $\mathrm{AD}$ signs during voiding. The outcome was deemed excellent when PVR was $\leqslant 100 \mathrm{ml}$ and $\leqslant 20 \%$, and dysuria was rated $\leqslant 2$

For the inpatients only, cystometry and cystourethrogram (in case of vesicoureteral reflux) were repeated 2-8 weeks after injection.

Further follow-up to evaluate the duration of effectiveness was carried out by clinical appointments and/or telephone consultations.

\section{Statistical analysis}

Paired $t$-tests were used to compare PVR and urodynamic data before and after injection. Qualitative values were compared using $X^{2}$-tests.

Bladder neck activity, detrusor contraction and level and severity of injury were tested as predictors of effectiveness using logistic regression. The relationship of each with PVR values was tested using analysis of variance.

Correlations between PVR before and after injection were analysed by using Pearson's or Spearman's methods.

A significance level of $P<0.05$ was used for all statistical comparisons.

\section{RESULTS}

Ninety-nine consecutive adult men with SCI (72 tetraplegic and 27 paraplegic) were included. All had an upper motor neuron syndrome. Mean age was $38.4 \pm 13.9$ years, and mean time since injury was $99.1 \pm 115.8$ months. Sixty patients were on oral $\alpha$-blockers (mainly alfuzosine or tamsulosine).

PVR was significantly reduced following urethral injection of botulinum toxin (from 227 to $98 \mathrm{ml}, P<0.01$ and from 63 to $27 \%$, $P<0.01$ ), as was dysuria (from 4.3 to $2.3, P<0.01$ ) (Table 1 ). $\mathrm{AD}$ signs, which were present in 82 patients before injection, were also significantly improved $(P<0.01)$ : they completely disappeared in 49 patients $(60 \%)$ and were ameliorated in a further 20 patients $(24 \%)$. The results were excellent (PVR $\leqslant 100 \mathrm{ml}$ and $\leqslant 20 \%$ and dysuria $\leqslant 2$ ) in 48 patients (48\%); of these, dysuria and $\mathrm{AD}$ signs completely disappeared in 37 .

In the 48 patients for whom the injections were effective, the effectiveness lasted for a mean of 6.5 months \pm 1.7 (2.0-10.0 months).

Twenty-five patients changed the voiding mode. Four patients with indwelling catheters regained spontaneous voiding, six shifted from clean intermittent catheterisation alone to spontaneous voiding and clean intermittent catheterisation and 14 others no longer required clean intermittent catheterisation. One patient who initially voided spontaneously required additional clean intermittent catheterisation.

Fifty patients had BND. BND was more frequent $(P<0.05)$ in men with paraplegia (19 out of 27 ) than in those with tetraplegia (31 out of 72 ).

There was a significant relationship $(P<0.01)$ between bladder neck activity and effectiveness. Thirty-six patients out of 49 with normal

Table 1 Results of the main outcome measures for the 99 patients

\begin{tabular}{|c|c|c|c|c|c|c|c|}
\hline & $P V R(m l)$ & PVR (\%) & Dysuria & Outcome & $A D$ signs & Retention & Voiding mode \\
\hline $\begin{array}{l}\text { Before } \\
\text { injection }\end{array}$ & $\begin{array}{l}227(133) \\
{[100-600]}\end{array}$ & $\begin{array}{c}63(24) \\
{[20-100]}\end{array}$ & $\begin{array}{c}4.3(0.6) \\
{[1-5]}\end{array}$ & - & Present in 82 & Present in 19 & $\begin{array}{l}51 \text { Spontaneous } \\
29 \text { Spontaneous+CIC } \\
15 \text { CIC only } \\
4 \text { Indwelling catheter }\end{array}$ \\
\hline Follow-Up & $\begin{array}{l}98(128) \\
{[0-400]}\end{array}$ & $\begin{array}{c}27(29) \\
{[20-100]}\end{array}$ & $\begin{array}{c}2.3(1.4) \\
{[1-5]}\end{array}$ & 48 Excellent & $\begin{array}{l}49 \text { Disappeared } \\
20 \text { Improved } \\
13 \text { Unchanged }\end{array}$ & $\begin{array}{l}4 \text { Excellent } \\
9 \text { Improved } \\
6 \text { Unchanged }\end{array}$ & $\begin{array}{l}68 \text { Spontaneous } \\
22 \text { Spontaneous+CIC } \\
9 \mathrm{CIC} \text { only } \\
0 \text { Indwelling catheter }\end{array}$ \\
\hline$P$ & $<0.01$ & $<0.01$ & $<0.01$ & $<0.01$ & $<0.01$ & $<0.01$ & \\
\hline
\end{tabular}

Abbreviations: AD, autonomic dysreflexia; CIC, clean intermittent catheterisation; PVR, post-void residual. 
Table 2 Relationship between excellent outcome and urodynamic, radiological and clinical data

\begin{tabular}{|c|c|c|c|c|c|c|c|c|}
\hline & \multicolumn{2}{|c|}{ Bladder neck } & \multicolumn{2}{|c|}{ Detrusor contraction } & \multicolumn{2}{|c|}{ Level of injury } & \multicolumn{2}{|c|}{ Severity of lesion } \\
\hline & Normal & $B N D$ & Present & Absent & Tetraplegia & Paraplegia & Motor complete & Motor incomplete \\
\hline Poor results $(n=51)$ & 13 & 38 & 43 & 8 & 30 & 21 & 43 & 8 \\
\hline$P$ & \multicolumn{2}{|c|}{$<0.01$} & \multicolumn{2}{|c|}{$<0.05$} & \multicolumn{2}{|c|}{$<0.01$} & \multicolumn{2}{|c|}{$=0.51$} \\
\hline
\end{tabular}

Abbreviation: BND, bladder neck dyssynergia.

Table 3 Relationship between bladder neck activity and main outcome measures

\begin{tabular}{|c|c|c|c|c|c|}
\hline & PVR (\%) & Dysuria & Outcome & $A D$ signs & Level of injury \\
\hline Normal bladder & $15(23)$ & 1.8 & 36 Excellent & 35 Disappeared & 41 Tetraplegic \\
\hline \multirow[t]{2}{*}{ neck $(n=49)$} & [20-100] & $(1.2)$ & & 7 Improved & 8 Paraplegic \\
\hline & & {$[1-5]$} & & 3 Unchanged & \\
\hline Bladder neck & $39(29)$ & 2.9 & 12 Excellent & 14 Disappeared & 31 Tetraplegic \\
\hline dyssynergia & [20-100] & $(1.4)$ & & 13 Improved & 19 Paraplegic \\
\hline$(n=50)$ & & [1-5] & & 10 Unchanged & \\
\hline$P$ & $<0.01$ & $<0.01$ & $<0.01$ & $<0.01$ & $<0.05$ \\
\hline
\end{tabular}

Abbreviations: AD, autonomic dysreflexia; PVR, post-void residual.

Dysuria: patient perception of dysuria, rated on a scale from 1 (absent) to 5 (maximum).

Values for PVR and dysuria are means, s.d. () and extremes [-]

opening were improved (73\%), compared with only 12 out of 50 with BND (24\%) (Table 2).

BND was significantly related to higher values of PVR (39\% vs $15 \%$, $P<0.01)$, dysuria $(2.9$ vs $1.8, P<0.01)$ and less improvement of $\mathrm{AD}$ signs (14 vs $35, P<0.01$ ) (Table 3 ).

Detrusor contraction and DSD were found during standard cystometry in 90 patients, and during the ice-water test in the remaining nine patients. There was a significant relationship between excellent outcomes and detrusor contraction found using standard cystometry; the outcome was excellent in 47 of these 90 patients (52\%) vs one out of nine with detrusor contraction found using the ice-water test $(11 \%)(P<0.05)$ (Table 2$)$.

Out of the 19 patients who had complete urinary retention, 13 resumed spontaneous voiding (68\%), although the result was excellent in only four $(21 \%)$. Three of these four patients had detrusor contraction during standard cystometry.

EMG showed continuous DSD (type 3 on the Blaivas classification) in 15 patients with total urinary retention. Excellent outcomes were obtained in three of them.

Excellent outcomes were related to the level of the lesion (more effective in the tetraplegia group, $P<0.01$ ), but not to the severity of the lesion (complete motor vs incomplete, $P=0.51$ ), nor to the time since SCI $(P=0.84)$ (Table 2$)$.

Logistic regression showed that detrusor contraction (odds ratio $=8.6$ ) and bladder neck activity (odds ratio $=7.1$ ) were strong predictors of excellent outcome, followed by level of injury (odds ratio $=4.3$ ). Analysis of variance showed a strong relationship between PVR after injection and detrusor contraction and normal bladder neck activity $(P<0.01)$, but not with level of injury $(P=0.12)$.

There was a strong correlation between PVR values before and after injection $(P<0.01$ and $r=0.58)$ (Figure 1). The correlation was

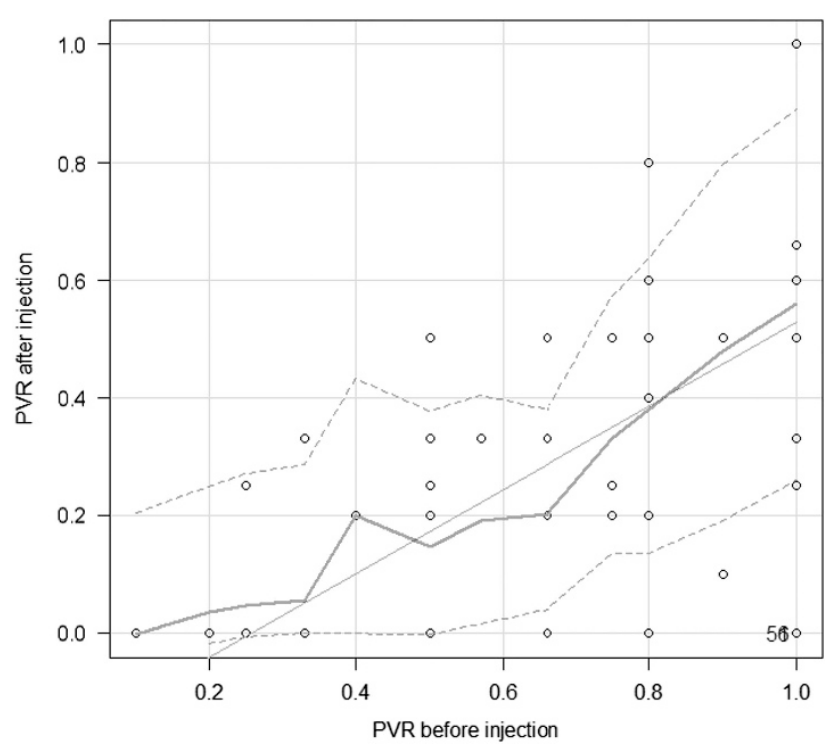

Figure 1 Correlation between post-void residual values before and after injection. PVR, post-void residual. Black line, correlation; grey line, reference; dotted line, Confidence Interval of 95\%.

stronger in men with tetraplegia (0.63) compared with those with paraplegia (0.53).

Follow-up cystometries were performed in 36 patients (mean 29.1 days \pm 9.3 ). Maximum detrusor pressure decreased slightly but not significantly $\left(-8 \mathrm{~cm} \mathrm{H}_{2} \mathrm{O}\right)$, as did detrusor leak point pressure $\left(-4 \mathrm{~cm} \mathrm{H}_{2} \mathrm{O}\right)$ and urethral pressure $\left(-5 \mathrm{~cm} \mathrm{H}_{2} \mathrm{O}\right)$. There was also a nonsignificant increase in bladder capacity $(+5 \mathrm{ml})$ (Table 4). 
Table 4 Results of the main urodynamic data

\begin{tabular}{lcccc}
\hline & $P$ Detrusor $\left(\mathrm{cm} \mathrm{H}_{2} \mathrm{O}\right)$ & DLPP $\left(\mathrm{cm} \mathrm{H} \mathrm{H}_{2} \mathrm{O}\right)$ & P Urethral $\left(\mathrm{cm} \mathrm{H} \mathrm{H}_{2} \mathrm{O}\right)$ & $\mathrm{B}=36$ \\
$\mathrm{n}=36$ & $\mathrm{n}=26$ & $135(45)[60-200]$ & $\mathrm{n}=36$ \\
\hline Before injection & $77(56)[0-240]$ & $68(27)[0-110]$ & $130(30)[70-200]$ & $272(170)[50-650]$ \\
Follow-Up & $70(38)[0-160]$ & $64(22)[0-100]$ & $=0.52$ & $=0.91$ \\
$P$ & $=0.52$ & $=0.83$ & $(139)[35-600]$ \\
\hline
\end{tabular}

Abbreviations: DLPP, detrusor leak point pressure; $\mathrm{P}$ detrusor, maximum detrusor pressure; $\mathrm{P}$ urethral, maximum urethral pressure.

Values are means, s.d. ( ) and extremes [-].

Vesicoureteral reflux was found in 11 men at baseline. Six underwent follow-up cystourethrogram that showed complete disappearance of the reflux in all.

Thirty-six patients underwent a second injection (31 with tetraplegia and five with paraplegia). The mean time between the two injections was 24.0 months \pm 30.5 (3-145 months). Cystourethrograms before this second injection showed the same pattern of bladder neck activity in all patients, including 17 patients with BND.

The outcomes of the second injection were similar in 32 out of 36 cases $(88.9 \%)$. They remained excellent in 22 out of 24 patients and poor in 10 out of 12 patients. The outcomes were different from the first injection in four men with tetraplegia: the treatment was no longer effective in two (all with BND) whose results had initially been excellent, whereas in two with poor initial outcomes the outcomes of the second injections were excellent (one with BND). The duration of effectiveness remained unchanged (6.0 months \pm 1.8 vs 6.2 months $\pm 2.1, P=0.56$ ).

\section{DISCUSSION}

DSD is defined as involuntary contractions of the detrusor muscle concurrent with involuntary contractions of the urethral striated muscle and/or periurethral striated muscle. ${ }^{11}$ DSD occurs after interruption of the spinal pathways, which connect the pontine and sacral micturition centres. ${ }^{2,12}$ In patients with suprasacral cord lesions, the frequency of DSD varies between 45 and $100 \%$, depending on the type of lesion. ${ }^{2,12}$

The rationale for treating patients with SCI and DSD with botulinum toxin is based on the results of two placebo-controlled studies $^{5,6}$ and other open studies. ${ }^{1,4-8,10,13-16}$ Most studies involved doses of $100 \mathrm{U}$ of botulinum toxin type A (Botox, Allergan). ${ }^{17}$ Two techniques have been described, involving endoscopic or transperineal approaches, with similar outcomes. ${ }^{16}$ Transperineal injections are safe and easy to perform by physicians trained in EMG. ${ }^{5,14}$ This technique is routinely used in our rehabilitation centre as it does not require any anaesthesia, and it can be used for both inpatients and outpatients.

The success rate of urethral injections of botulinum toxin varies depending on the outcome measures used. We found excellent results in $48 \%$ of the patients, based on very strict criteria that combined objective (PVR $\leqslant 100 \mathrm{ml}$ and $\leqslant 20 \%$ ) and subjective (dysuria $\leqslant 2$ ) clinical parameters. The 6.5-month duration of effectiveness found in this study is in line with some studies, ${ }^{4,7,15}$ whereas others found shorter durations of around 3 months. ${ }^{1,8}$

PVR is a clinically important parameter, and it has been found to improve in all studies of botulinum toxin treatment. In a recent pooled analysis, which included eight studies and 129 patients with SCI, there was a mean decrease in PVR of $99 \mathrm{ml}$ (from 252 to $153 \mathrm{ml}$ ) at 1 month, which is quite similar to the mean $129 \mathrm{ml}$ decrease in PVR found in our study (from 227 to $98 \mathrm{ml}$ ). ${ }^{17}$ However, PVR alone may not be the most relevant parameter on which to base the outcome. ${ }^{18}$ The results for urodynamic parameters are conflicting and not necessarily correlated with clinical improvement. ${ }^{17}$ Detrusor pressure may ${ }^{7,8}$ or may not be improved, ${ }^{1,4,5,13}$ detrusor leak point pressure either remains unchanged ${ }^{4,13}$ or decreases significantly. ${ }^{8}$ Only decreases in urethral pressure have been systematically reported. We did not find any significant change in any of these parameters, but care must be taken in interpretation, as follow-up cystometries were performed in a limited number of patients $(n=36)$.

Patient-reported outcomes and quality of life have rarely been addressed in studies. Interestingly, $\mathrm{Kuo}^{7,15}$ reported that despite excellent urodynamic outcomes (61\%) the level of satisfaction of patients with SCI was relatively poor. de Seze et al. ${ }^{5}$ also assessed patient satisfaction using a visual analogue scale from 0 to 10. We designed a simple scale to evaluate dysuria. The results demonstrated significant improvement of this subjective symptom, with total disappearance in most patients who had excellent results.

$\mathrm{AD}$ is generally improved in most patients ${ }^{4,5,7,8,13}$ but not all. ${ }^{1}$

Change in voiding mode has been reported in most studies, and it is of clinical importance. ${ }^{17}$ In our study, 18 patients no longer required permanent or intermittent catheterisation following sphincter injection, and the frequency of intermittent catheterisation was reduced in another 6 .

There was a significant relationship between bladder neck activity and outcome, as only 12 out of 50 patients with BND (24\%) had excellent results. Logistic regression further showed bladder neck activity to be a strong predictor of effectiveness (odds ratio $=7.1$ ). BND is defined as a functional contraction of the bladder neck that occurs during detrusor contraction, and it is independent of DSD or the severity of the lesion. ${ }^{1,19}$ BND has been found to be one of the main reasons for failure of sphincterotomy. The reported rate of secondary BND after surgical sphincterotomy varies considerably, up to $50 \%$ in patients with tetraplegia, whereas after urethral stenting $7-20 \%$ of patients require secondary bladder neck incision or resection. ${ }^{20}$ The significance of BND had already been highlighted in some studies of urethral injections of botulinum toxin. ${ }^{1,7} \alpha$-Blockers are first-line treatments for bladder outlet obstruction either before or after a failed sphincterotomy. ${ }^{1,19}$

Detrusor overactivity is common in patients with SCI who have a suprasacral lesion and an upper motor neuron syndrome. However, detrusor contractility can also be reduced, compromising the result of sphincterotomy. Our results showed that the presence of detrusor contraction during normal bladder filling is strongly related to the effectiveness of botulinum toxin injection, and it is a strong predictor of outcome (odds ratio $=8.6$ ). Provocative tests, such as the ice-water test, are thus useful for diagnosis but are not functional and should not be used for this purpose. These results illustrate that, even though patients can regain sustained detrusor contractility after a single 
injection of urethral botulinum toxin, detrusor underactivity or areflexia can persist. ${ }^{1,10}$

The Blaivas classification is commonly used to grade DSD. It differentiates three types of DSD according to the pattern of external urethral sphincter electromyographic activity. DSD can also be characterised simply as intermittent or continuous according to the type of sphincter contractions that occur during the detrusor contraction. ${ }^{2,21}$ The effects of urethral botulinum toxin injection have not yet been studied as a function of the type of dyssynergia. However, one study showed that sphincter activity became intermittent in patients with initially strong, continuous DSD, with a significant reduction in integrated EMG. ${ }^{13}$ Our results showed that treatment outcome was related to the severity of DSD, with a strong correlation between PVR values before and after injection. Results in patients on urinary retention because of continuous DSD (type 3 in the Blaivas classification) were generally poor; only $20 \%$ had an excellent outcome (three out of 15 patients).

Our results showed that the level of injury, but not the severity, influenced outcome. These results cannot be explained by the severity of DSD, as the opposite relationship has been found with DSD. It is more frequent and more severe in patients with complete spinal cord lesions, with no relationship with lesion level. ${ }^{12}$ This again highlights the role of BND, which was significantly more frequent in the men with paraplegia than in those with tetraplegia in the present study. Two types of BND have been described, which may differ between tetraplegia and paraplegia: one is secondary to $\mathrm{AD}$ and the other is associated with loss of supraspinal inhibitory control on the vesico-sympathetic reflex. ${ }^{19}$

Vesicoureteral reflux is known to improve after surgical sphincterotomy or urethral stenting, ${ }^{3,9}$ or urethral injection. ${ }^{8,13}$ Our study confirms this, as reflux was found to have disappeared in all patients who underwent repeat cystourethrograms.

Only two studies have evaluated the effect of repeat injections. $\mathrm{Kuo}^{15}$ reported satisfactory outcomes in 11 patients with SCI, and Liao and $\mathrm{Kuo}^{10}$ found that the therapeutic result was as good as following the first treatment in all 21 patients with neurogenic and non-neurogenic bladder. We showed that the effectiveness of repeat injections was similar to that of initial injections in most patients (89\%). If the initial injection had a low level of effectiveness, the chances of an excellent outcome with repeat injection were low (two out of 12 patients, 17\%). When injections were effective, the effectiveness lasted for the same duration (6.0 months vs 6.2 months, $P=0.85)$.

\section{CONCLUSION}

Our results showed that detrusor contraction and bladder neck opening are predictors of excellent outcome following urethral injection of botulinum toxin for DSD. Paraplegia (rather than tetraplegia) and severe DSD were associated with poorer outcomes. Outcome following repeat injection was mostly the same as following initial injection. The outcome predictors found in this study can be used to improve the selection of appropriate patients for treatment of DSD by botulinum toxin injection, thus improving outcomes.

\section{DATA ARCHIVING}

There were no data to deposit.

\section{CONFLICT OF INTEREST}

The authors declare no conflict of interest.

\section{ACKNOWLEDGEMENTS}

We are grateful to Dr Vincke Bernard, MD, Fondation Hopale, for statistical assistance.

1 Schurch B, Hauri D, Rodic B, Curt A, Meyer M, Rossier AB. Botulinum-A toxin as a treatment of detrusor-sphincter dyssynergia: a prospective study in 24 spinal cord injury patients. J Urol 1996; 155: 1023-1029.

2 Blaivas JG, Sinha HP, Zayed AA, Labib KB. Detrusor-external sphincter dyssynergia: a detailed electromyographic study. J Urol 1981; 125: 545-548.

3 Chancellor MB, Bennett C, Simoneau AR, Finocchiaro MV, Kline C, Bennett JK et al. Sphincteric stent versus external sphincterotomy in spinal cord injured men: prospective randomized multicenter trial. J Urol 1999; 161: 1893-1898.

4 Chen SL, Bih LI, Chen GD, Huang YH, You YH. Comparing a transrectal ultrasound-guided with a cystoscopy-guided botulinum toxin a injection in treating detrusor external sphincter dyssynergia in spinal cord injury. Am J Phys Med Rehabil 2011; 90: 723-730.

5 de Seze M, Petit H, Gallien P, de Seze MP, Joseph PA, Mazaux JM et al. Botulinum a toxin and detrusor sphincter dyssynergia: a double-blind lidocaine-controlled study in 13 patients with spinal cord disease. Eur Urol 2002; 42: $56-62$.

6 Dykstra DD, Sidi AA, Scott AB, Pagel JM, Goldish GD. Effects of botulinum A toxin on detrusor-sphincter dyssynergia in spinal cord injury patients. J Urol 1988; 139: 919-922.

7 Kuo HC. Satisfaction with urethral injection of botulinum toxin A for detrusor sphincter dyssynergia in patients with spinal cord lesion. Neurourol Urodyn 2008; 27: 793-796.

8 Tsai SJ, Ying TH, Huang YH, Cheng JW, Bih LI, Lew HL. Transperineal injection of botulinum toxin $\mathrm{A}$ for treatment of detrusor sphincter dyssynergia: localization with combined fluoroscopic and electromyographic guidance. Arch Phys Med Rehabil 2009; 90: 832-836

9 Game X, Chartier-Kastler E, Ayoub N, Even-Schneider A, Richard F, Denys P. Outcome after treatment of detrusor-sphincter dyssynergia by temporary stent. Spinal Cord 2008; 46: 74-77.

10 Liao YM, Kuo HC. Causes of failed urethral botulinum toxin A treatment for emptying failure. Urology 2007; 70: 763-766.

11 Abrams P, Cardozo L, Fall M, Griffiths D, Rosier P, Ulmsten U et al. The standardisation of terminology of lower urinary tract function: report from the Standardisation Sub-committee of the International Continence Society. Neurourol Urodyn 2002; 21: 167-178.

12 Schurch B, Schmid DM, Karsenty G, Reitz A. Can neurologic examination predict type of detrusor sphincter-dyssynergia in patients with spinal cord injury? Urology 2005; 65: 243-246.

13 Chen SL, Bih LI, Huang YH, Tsai SJ, Lin TB, Kao YL. Effect of single botulinum toxin A injection to the external urethral sphincter for treating detrusor external sphincter dyssynergia in spinal cord injury. J Rehabil Med 2008; 40: 744-748.

14 Gallien P, Robineau S, Verin M, Le Bot MP, Nicolas B, Brissot R. Treatment of detrusor sphincter dyssynergia by transperineal injection of botulinum toxin. Arch Phys Med Rehabil 1998; 79: 715-717.

15 Kuo HC. Therapeutic outcome and quality of life between urethral and detrusor botulinum toxin treatment for patients with spinal cord lesions and detrusor sphincter dyssynergia. Int J Clin Pract 2013; 67: 1044-1049.

16 Schurch B, Hodler J, Rodic B. Botulinum A toxin as a treatment of detrusor-sphincter dyssynergia in patients with spinal cord injury: MRI controlled transperineal injections. J Neurol Neurosurg Psychiatry 1997; 63: 474-476.

17 Mehta S, Hill D, Foley N, Hsieh J, Ethans K, Potter P et al. A meta-analysis of botulinum toxin sphincteric injections in the treatment of incomplete voiding after spinal cord injury. Arch Phys Med Rehabil 2012; 93: 597-603.

18 Chancellor MB, Elovic E, Esquenazi A, Naumann M, Segal KR, Schiavo G et al. Evidence-based review and assessment of botulinum neurotoxin for the treatment of urologic conditions. Toxicon 2013; 67: 129-140.

19 Schurch B, Yasuda K, Rossier AB. Detrusor bladder neck dyssynergia revisited. J Urol 1994; 152: 2066-2070.

20 Denys P, Thiry-Escudie I, Ayoub N, Even-Schneider A, Benyahya S, Chartier-Kastler E. Urethral stent for the treatment of detrusor-sphincter dyssynergia: evaluation of the clinical, urodynamic, endoscopic and radiological efficacy after more than 1 year. J Urol 2004; 172: 605-607.

21 Karsenty G, Reitz A, Wefer B, Boy S, Schurch B. Understanding detrusor sphincter dyssynergia-significance of chronology. Urology 2005; 66: 763-768. 